\title{
Present Situation and Suggestions of Personal Performance Evaluation of Clinical Departments Based on Medical Quality
}

\author{
Wen Wang1, Luman Ye ${ }^{2}$, Yubo Zhang3 ${ }^{\text {, Yunfei He}}{ }^{1}$, Kexin Sun ${ }^{4}$, Li Huang5* \\ ${ }^{1}$ Research Center for Medicine and Social Development, Innovation Center for Social Risk Governance in Health, School of Public \\ Health and Management, Chongqing Medical University, Chongqing, China \\ ${ }^{2}$ Chonggang Hospital, Chongqing, China \\ ${ }^{3}$ Chongqing Cancer Hospital, Chongqing, China \\ ${ }^{4}$ First Clinical College, Chongqing Medical University, Chongqing, China \\ ${ }^{5}$ The First Affiliated Hospital of Chongqing Medical University, Chongqing, China \\ Email: ww496414145@163.com, *1h2015@sina.com
}

How to cite this paper: Wang, W., Ye, L.M., Zhang, Y.B., He, Y.F., Sun, K.X. and Huang, L. (2019) Present Situation and Suggestions of Personal Performance Evaluation of Clinical Departments Based on Medical Quality. Open Journal of Social Sciences, 7, 293-303.

https://doi.org/10.4236/jss.2019.78021

Received: July 18, 2019

Accepted: August 20, 2019

Published: August 23, 2019

Copyright $\odot 2019$ by author(s) and Scientific Research Publishing Inc. This work is licensed under the Creative Commons Attribution International License (CC BY 4.0).

http://creativecommons.org/licenses/by/4.0/

\begin{abstract}
To understand the status quo of performance evaluation of clinicians and explore the improvement of personal performance evaluation system, by means of literature research, the individual performance evaluation of the clinical department in recent years was combed, and the clinicians' individual performance in a department of third-level cancer hospital was analyzed in this paper. The literature research showed that the researches on hospital performance and quality evaluation system in China in the past 20 years had gradually deepened, but it needed to be further improved on the construction of individual performance assessment system within the department. The case study showed that the individual performance assessment of the department needed to combine the characteristics of specialized medical treatment to make up for the deficiencies. The main reasons that affected the effectiveness of individual performance evaluation in clinical departments were the lack of measures and attention, which should be started from all level of departments and personnel.
\end{abstract}

\section{Keywords}

Individual Performance, Medical Quality, Clinical Departments

\section{Introduction}

With the continuous deepening of China's medical and health system reform, 
performance appraisal is the focus and difficulty of research. The individualized evaluation of clinicians is the soul of the index system [1]. As providers of medical services, clinicians directly affect the quality and level of hospital medical services [2], and reasonable individual performance evaluation is an important part of departmental performance management. In May 2019, the performance appraisal index published in the "Operation Manual of Performance Appraisal for Third-level State Public Hospitals" included medical quality and satisfaction index, which clearly defined the medical service orientation of safety quality priority for third-level public hospitals and paid attention to the satisfaction of medical staff. By analyzing the problems existing in the medical quality and performance appraisal of gastrointestinal cancer center in a tertiary specialized hospital, this paper puts forward some suggestions to improve the personal performance appraisal in the department and promote the medical quality management.

\section{Materials and Methods}

\subsection{Sources}

The data came from the relevant policies, documents and regulations of hospital performance appraisal in China, and the medical quality assessment scores of gastrointestinal cancer center of $Z$ Hospital affiliated to a university in Chongqing from January 2016 to December 2018. Take the current situation of Z Hospital as an example, to analyze and sort out the history, current situation and problems of performance appraisal in China, and to provide policy recommendations for personal performance allocation in the department.

\subsection{Research Methods}

In the literature analysis, 6048 articles were retrieved from CNKI from 2000 to 2018 with the key words of "personal performance appraisal or medical quality" (See Figure 1). A total of 746 articles were searched in PubMed database from 2000 to 2018 (See Figure 2). The collected literature was analyzed. From the perspective of time distribution, the number of literatures increased from markedly to almost steadily.

Case study method was used. Z Hospital is a tertiary public oncology hospital, which integrates medical treatment, teaching, scientific research, prevention and rehabilitation. It has 1480 beds and 34 clinical and medical departments. In recent years, the hospital has played a leading role in the tertiary specialized hospitals, and the oncology specialty alliance has achieved remarkable results [3]. Gastrointestinal surgery is one of the clinical operating departments of the hospital. In 2017, the Gastrointestinal Cancer Center was established, which mainly focuses on patients with colorectal cancer treated by surgery, radiotherapy and chemotherapy. There are 80 beds, 20 clinicians, 3 chief physicians, 2 deputy chief physicians, 11 attending physicians and 4 residents. The number of patients admitted to this department has risen year after year in the past three years, and 


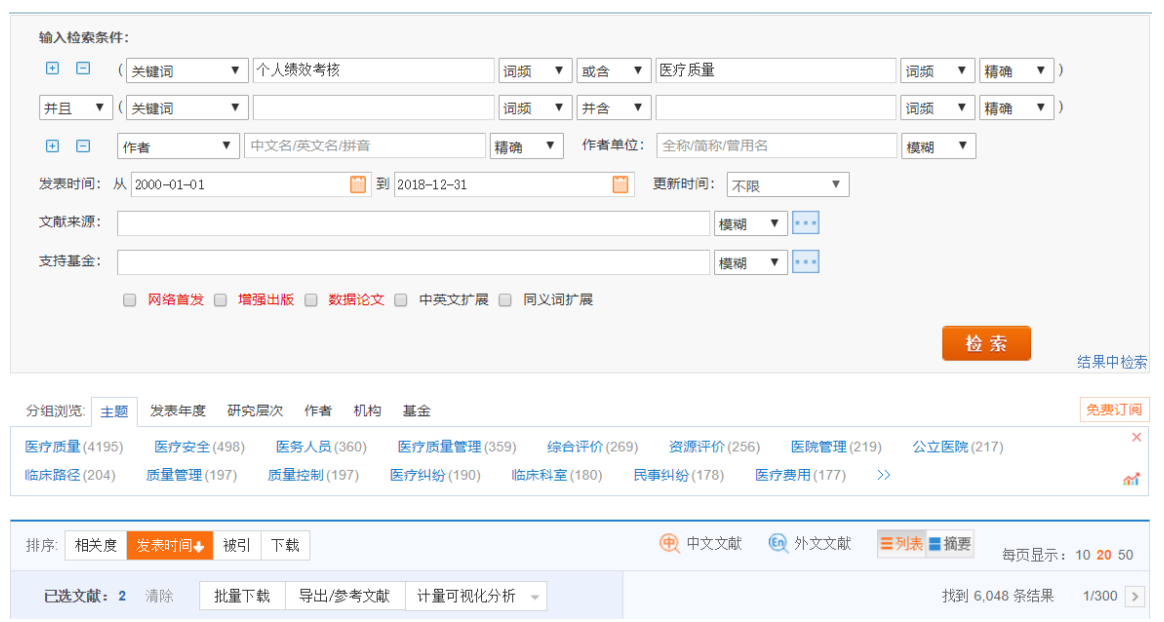

Figure 1. The search result screenshot of CNKI.

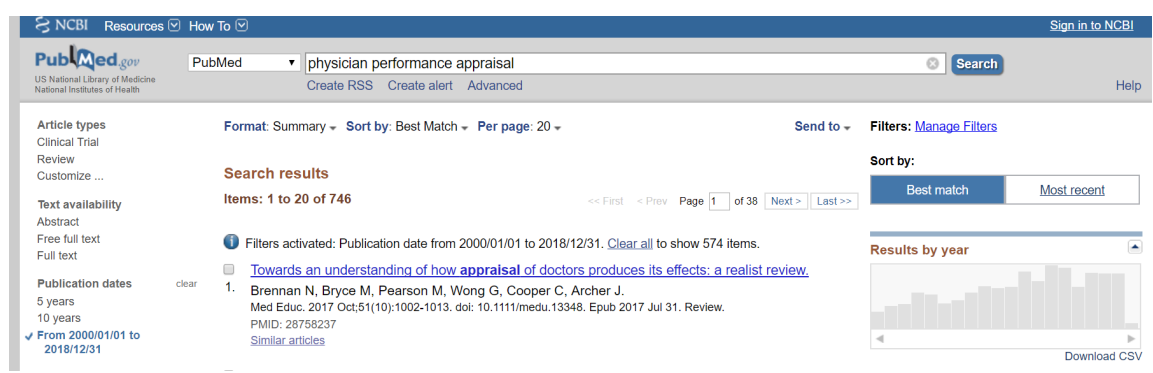

Figure 2. The search result screenshot of PubMed.

the number of outpatient visits reached 9527 in 2018 . The statistics of outpatients increased by $10.1 \%$ in 2017 and $9.18 \%$ in 2018. In the last three years, discharged patients increased by $23.6 \%$ and $19.28 \%$ year by year. The increase of operations was $36.9 \%$ and $15.88 \%$ respectively.

$\mathrm{Z}$ Hospital carried out performance at the hospital and department levels, which mainly focused on the comprehensive performance evaluation at the department level. After the evaluation, the results were reported, and the corresponding amount of performance bonus would be deducted by the medical department. Personal assessment in gastrointestinal surgery tended to be based on years of work, professional and technical level, so performance management was extensive. Doctors' post competency, labor value and responsibilities were not fully reflected, and the enthusiasm of staff was not effectively stimulated. Although a performance appraisal group was set up within the department, the individual performance plan was too simple and there was lack of particularity and personalization [4]. On the one hand, the assessment mode with workload as the core may cause the existence of quality risks. On the other hand, there was insufficient feedback on the quality assessment results and no perfect reward and punishment mechanism at the hospital level. Therefore, doctors' satisfaction of compensation was affected.

With the rapid increase of patients, the possibility of potential medical hazards increased. It was urgent to put various medical systems into practice to in- 
vestigate and eliminate medical accidents in departments. Therefore, attention to the quality of medical treatment had become the most important task of departments. The monthly assessment of hospital medical work mainly included work efficiency index and quality index. Monthly quality assessment, such as medical insurance management, rational drug use, medical quality, carried out in accordance with the relevant hospital documents. Among them, the weight of the total score of medical quality assessment was composed of 85 points of medical quality, 10 points of nursing quality and 5 points of scientific research and teaching weight. Because of the difference in the quality of nursing, research and the personnel involved in the assessment, they were not included. Some indicators were qualitative indicators and there was no regularity, this paper only analyzes the medical quality of the department in recent years.

\section{Results}

\subsection{Literature Research Results}

Invalid information was deleted, such as assessment of therapies and treatment, clinical guidelines, medical education, etc. From the main content point of view, foreign hospitals generally implement third-party assessments, mainly involving assessment methods, tools and effect feedback. Most of the research on performance appraisal of public hospitals in China involved performance indicators and system construction. The assessment level was mainly the operation performance of hospitals, departments, and the management performance of clinic department director [5]. Less attention was paid to specialist hospitals, especially the individual performance appraisal of department interiors was insufficient. Although there were many researches on the methods of medical quality evaluation in departments, how to improve the enthusiasm and satisfaction of employees and the quality of specialist medical care in clinical departments was a problem worthy of discussion.

\subsection{Case Study Results}

According to the monthly scores of the medical quality assessment of the departments in the past three years, there were three scores in 2016 that are higher than the average score level of the hospital. In 2017, there were two higher than the average level of surgery (see Figure 3). In 2018, only one is higher than the average score of the hospital (see Figure 4).

The monthly clinical medical quality assessment project totals 1000 points. The content of the assessment was: 1) The quality of diagnosis and treatment was 200 , which was most valued by the hospital management. 2) Learning, activity records, ethics construction, quality of medical records, rational use of drugs, infection management, and other aspects, each accounted for 100 points.

According to the medical deduction items (see Table 1), in the past three years, the deductions of quality of diagnosis and treatment were between 72 to 142 points, quality of medical records were all higher than 93, and activity 


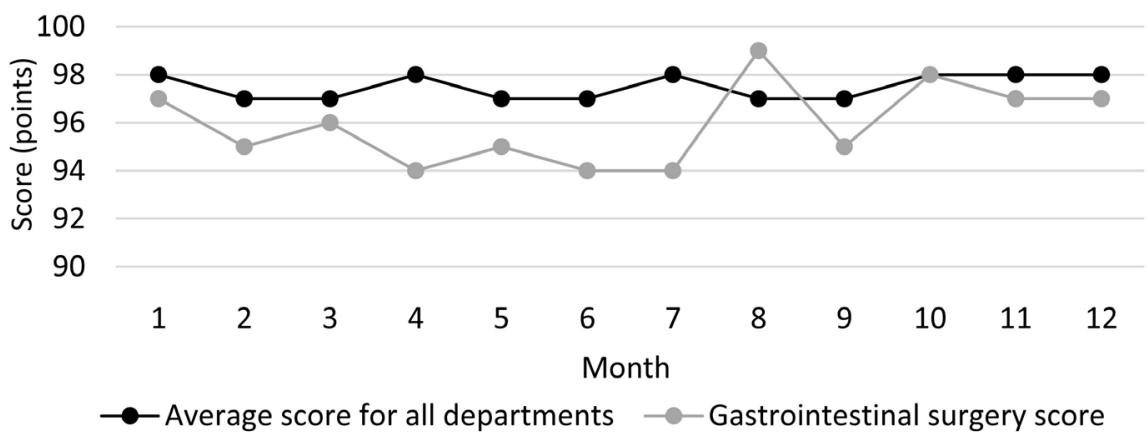

Figure 3. Scores of gastrointestinal surgery and hospital quality assessment in 2017.

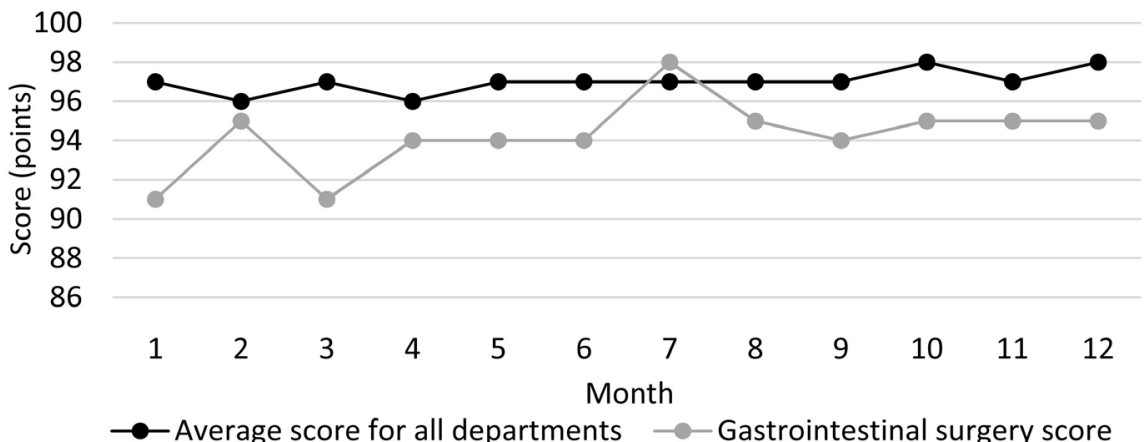

Figure 4. Scores of gastrointestinal surgery and hospital quality assessment in 2018.

Table 1. Medical deduction points of gastrointestinal surgery in recent years.

\begin{tabular}{ccccccccc}
\hline Year & $\begin{array}{c}\text { Quality of } \\
\text { diagnosis } \\
\text { and } \\
\text { treatment }\end{array}$ & Learning & $\begin{array}{c}\text { Activity } \\
\text { records }\end{array}$ & $\begin{array}{c}\text { Ethics } \\
\text { construction }\end{array}$ & $\begin{array}{c}\text { Quality } \\
\text { of medical } \\
\text { records }\end{array}$ & $\begin{array}{c}\text { Rational } \\
\text { use of } \\
\text { drugs }\end{array}$ & $\begin{array}{c}\text { Infection } \\
\text { management }\end{array}$ & Other \\
aspects
\end{tabular}

records were above 96 in these years. Rational drug use deducted suddenly in 2017, then increased to 215 in 2018. These items were the most significant deduction, among which the latter two points increased year by year. The deduction points for infection management and other aspects showed a decreasing trend, reduced from 55 to 36 and 38 to 11 respectively. However, the deduction of points appeared in the ethic constructions. As the workload of the department increased, the management of the department should focus on the improvement of medical quality.

\section{Discussion}

\subsection{The Individual Assessment Indicators Were Incomprehensive}

The specialist hospital was mainly based on cancer surgery, radiotherapy and chemotherapy. So, there were great differences among types of cancer. The qual- 
ity control was not detailed. The quality assessment indicators performance evaluation within department were imperfect. The individual assessment indicators were lacking. Because the gastrointestinal contents and the purulent exudate in the abdominal cavity of patients with gastrointestinal tumor surgery in this department were prone to cause incision contamination, the possibility of postoperative infection was high. Therefore, the choice of antibacterial drugs and nutritional support for enteral and external needs depend on the patient's condition. Relevant indicators related to specialist quality such as intestinal anastomotic leakage, incision infection rate, and unplanned reoperation quality were not included in the performance appraisal of department members.

\subsection{Individual Performance Was Not Combined with Hospital Strategy}

In recent years, the number of patients in this department increased, and the operation time of doctors was long. It was easy to cause complaints and disputes due to delayed submission of medical record information, absence of medical system training, poor attitude in communication and service to patients. The hospital strategy focused on medical quality construction; however, each surgical department was required to strengthen the surgical capability and teamwork. Combining the characteristics of the industry and the actual innovation incentive and restraint mechanism, hospital strove to embody the value of medical personnel's technical and labor services, so as to provide quality and efficient tumor diagnosis and treatment services for the people. The performance of individuals emphasized who worked more could get paid more, but other aspects like activity record was unrelated to their own payment. The responsibilities were unclear, leading to prevarication, procrastination and even omission. With the rapid increase of patients, the quality management target was not clear and the medical quality could not be ignored while improving medical efficiency.

When department director conducted individual performance distribution, there were often many drawbacks in the process. The distribution method was not appropriate. The reference of evaluation was insufficient. The information platform was not fully utilized, and the data on the quality and quantity of work were incomplete. As a result, the performance of wage distribution was largely dependent on the subjective impression of the director.

\subsection{Administrators and Individuals Were Not Paying Enough Attention}

The performance appraisal indicators included the evaluation system of the hospital and each department level. In addition, the evaluation of the members of the department should also be improved. In view of the results of medical quality evaluation at the hospital level, the assessment at the department level was insufficient. For example, after the medical record examination, the deducted performance bonus was shared by the attending physicians and resident physicians. After the responsibility layer was decomposed, the relevant personnel did 
not pay much attention.

Although the hospital clearly defined the performance allocation authority of the department director, it usually only emphasized the income but ignored the management [6]. The workload of the doctors was the basis of the individual performance distribution within the department, thus leading to lack of responsibility for quality management of medical services.

\subsection{Performance-Related Training and Communication Were Neglected}

The department had insufficient feedback on the hospital level evaluation. For example, deductions of perioperative quality check were mainly caused by incomplete preoperative discussion content, imperfect preventive measures for postoperative complications, etc. Repeated occurrences were still unresolved. Since the quality management results was delivered in each department in the form of documents each month, however, the department did not pay attention to it. There was a lack of effective quality control communication with medical staff, resulting in insufficient link and process control [7]. Improper use of assessment results, lack of feedback mechanism, emphasis on assessment, and neglect of communication made the problem repeated, which were unfavorable for the performance and ability improvement of the examinees. At the same time, an inconsistent understanding of the staff and nonacceptance of performance appraisal results could not mobilize the enthusiasm of medical staff and dampen the enthusiasm of the clinicians. It was inconducive to creating a reasonable competitive environment and the improvement of the technical level of the department.

\section{Recommendations}

This study combined theoretical research method and case study method to explore several suggestions for improving the internal personal performance appraisal scheme of clinical departments.

\subsection{Appropriately Adjust the Individual Performance Evaluation Indicators and Weights}

The clinical departments are with many operations, high risk factor and high work intensity, so the performance assessment is difficult to cover all aspects. With the increase of patients, the indicators, weights and scoring standards of the personal performance evaluation in the department should be dynamically adjusted according to the development of the department, and linked to the individual performance bonus, so as to induce the improvement of the quality score of the department. Development stage is different, the content of performance appraisal should also have special emphasis. According to the monthly department quality assessment, the individual performance assessment should be adjusted appropriately. The sub-standard indicators should be strengthened, 
new indicators should be added, and the indicators that have reached the standard should be weakened [8]. Hospitals can unify the criteria for individual performance of clinical departments, such as the antibiotic use rate, the rate of grade A medical records, the percentage of drug expenditure, and others as common indicators of medicine and surgery departments, and then select the number of surgical cases, the workload of medical teams, specialist indicators as individual evaluation indicators of surgery [9]. According to the "Performance Appraisal Opinions of Third-level Public Hospitals" and the evaluation framework at the hospital level, the indicators are decided by the performance appraisal group and integrated into the internal performance appraisal content of the department. Therefore, the assessment is based on evidence, and the bonus distribution results are not easy to deviate.

The personal performance evaluation system of the clinicians should focus on monitoring the medical process rather than implementing the corresponding deductions within the department only after the results of the department quality assessment are announced. Appropriately improve the evaluation of the quality of medical care in the distribution of clinicians' bonus, and to promote quality. In this way, the process of tumor diagnosis and treatment and the use of chemotherapy drugs are standardized, so that the tumor diagnosis and treatment process is scientific and reasonable. In addition, the causes and quality control of intestinal anastomotic leakage in this department, statistical analysis of incision infection rate, quality control of unplanned reoperation and cause analysis need to be included in the personal assessment of clinicians to further improve the surgical operation process.

\subsection{Combine Individual Performance with Organizational Strategy}

Individual performance allocation of departments should focus on outstanding problems in medical quality. The purpose of performance assessment is to improve the overall operation quality and efficiency of hospitals. The whole hospital should be closely linked, and the individual goal should be unified with the hospital goal, so as to improve the overall performance of the hospital while improving the overall performance of the individual and the department. Therefore, the evaluation goal at the department level must be combined with the strategy of hospital quality construction. The increase in the number of patients and workload brings direct performance rewards, so that doctors focus on the improvement of workload and business development, and the opportunity of quality risk increases accordingly. The implementation and effectiveness of assessment should be guaranteed. For example, with the increase of discharged patients, on the basis of carrying out special rectification on the front page of medical records, doctors should strengthen the examination of key medical records, such as difficult cases records, death cases records, surgical medical records and blood transfusion medical records. Promptly and effectively supervise the filing of discharge medical records. 


\subsection{Improve the Evaluation Mechanism at the Department Level}

In hospital performance assessment, medical service quality is essential. Hospitals can organize internal and external assessment. Questionnaire survey and cross assessment in various forms to ensure that the assessment results are open and transparent, which is conducive to the improvement of medical service quality and the realization of fairness and justice [10]. And try to avoid problems such as equalitarianism, subjective judgment and arbitrariness caused by improper management [11].

Make full use of the organizational structure of the quality and safety management group and the performance appraisal group of the department. Define the responsibilities of each work, and standardize the department's direction and personal goals. To ensure the comprehensiveness of indicators such as medical disputes and complaints in the work of clinicians, use of antibiotics in perioperative period, and clinical pathway enrollment rate, etc. Consideration should be given to positive incentives and negative incentives for the department's individual performance. And closely combine with the development status of hospitals and individual needs of department members. The incentive mechanism may be ineffective for doctors if the bonus is too low or the superior fails to give a certain reward according to the regulations. The performance assessment group in the department should develop the spirit of democracy, solicit the opinions of members extensively, and enhance the sense of personal participation. In the event of a medical quality problem, the examinees are encouraged to make positive improvements. Adjust the examination method of medical service quality, ensure the real and reliable source of the evaluation data, and quantify the index. With the improvement of information technology, making full use of information data monitoring and statistical analysis and hospital information management system [12], and reducing evaluation with subjective factors can better measure the quality of medical services.

\subsection{Pay attention to Communication and Training of Performance Evaluation Results}

The hospital needs to increase supervision and guidance on the performance distribution of the department. Due to the constraints of manpower and professional conditions, the performance-related department should provide guidance to the clinical departments to help them solve the problems such as difficult implementation of performance measures and passive acceptance of assessments [13]. As the executive of the hospital policy and the leader of the department's work, the director of the department should take the responsibility and integrate the performance concept into the culture of the department. To change the status quo of departmental emphasis on income and neglect of management, some actions must be taken. Make clear the duties and objectives of the director from the hospital level, strengthen the management ability and responsibility consciousness of the department director, and make the performance evaluation of 
the department change from focusing on economic efficiency assessment to medical quality, job responsibilities, and other aspects.

The staff in the department should have a full understanding of the content and methods of the assessment, and it is particularly crucial to carry out training for the department director and relevant personnel. For the development of the department's personal assessment work, it is necessary to do a good job in training before it becomes effective, and hold all kinds of discussion meetings of various members according to the actual situation. Communicate and feedback the results of the medical quality assessment during the design and implementation of the performance plan. Discussion and communication by frontline medical staff can reduce the occurrence of resistance in evaluation. It is necessary to eliminate the thought concerns of the examinees, improve the understanding of the performance plan, cooperate with the management personnel, and promote the overall and individual performance of the department. Make full use of the department's individual performance evaluation, reduce the deduction of medical quality control points, improve the overall work quality and staff enthusiasm, and achieve the long-term and benign development of the department.

\section{Conclusion}

The quality of medical care has direct impacts on the sustainable development ability of hospitals. The management of medical care quality of departments should not only stop at the level of deducting part of bonus due to substandard quality control indicators, but also should further combine individual performance evaluation and salary distribution system. From the perspective of hospital, we should strengthen supervision and guidance, implement the operating methods of public hospital performance appraisal, cooperate closely with all departments, and improve various supporting systems. At the same time, from the department's internal individual performance assessment, it can improve the quality management results linked to the assessment and reward and punishment system. Making sure the individual performance assessment is effective and acceptable to staff.

\section{Fund Program}

1) Research on the Optimization of Performance Management in Large Public Hospitals (2018ZDXM013).

2) Research on the Implementation of Modern Hospital Management System.

3) Research on performance wage Reform in large Public Hospitals.

4) Research on Subject Construction and Talent Development Planning in 2020-2030 of the First Affiliated Hospital of Chongqing Medical University.

\section{Conflicts of Interest}

The authors declare no conflicts of interest regarding the publication of this paper. 


\section{References}

[1] Zheng, S.W. and Wang, A. (2016) Probing into the Performance Evaluation System of Physicians with Advanced Technical Title. Chinese Hospital Management, 36, 67-68.

[2] Lu, Y.J., Sun, Y.J., Mo, J.Y. and Wang, Y. (2016) Construction of Modular Performance Distribution Model for Clinical Doctors in Public Hospital. Chinese Hospital Management, 36, 73-75.

[3] Lu, Y.J. and Wu, Y.Z. (2017) Exploration on the Model of Cancer Specialized Medical Union in Chongqing. Chinese Journal of Hospital Administration, 33, 576-578.

[4] Hu, X.Q. and Hong, D.D. (2017) Analysis on Common Problems and Countermeasures of Performance Evaluation in Public Hospitals. Chinese Health Economy, $36,83-84$.

[5] Dai, Z.M. (2018) Research on Misunderstanding and Improvement Strategy of Hospital Performance Management. Chinese Health Economy, 37, 76-78.

[6] Shen, J.H. (2018) Research on the New Model of Performance Management of Hospital Departments led by the Director. Health Economy Study, 7, 57-58.

[7] Lei, J.H. (2019) Analysis and Exploration of Public Hospital Budget Performance Management. Chinese Health Economy, 38, 86-88.

[8] Zheng, S.W., Wang, A. and Ma, J.H. (2015) Analysis on the Effect of Performance Evaluation System of Cancer Specialist Hospital. Chinese Hospital Management, 35, 53-54.

[9] Zhang, L.J. (2018) Practice and Reflection on the Secondary Distribution of Performance Bonus in Medical Technology Departments: A Case Study of Ultrasonic Medicine and Radiology. Finance and Accounting Learning, 15, 194-195.

[10] Ma, J., Guo, Y.L., Jiang, J.Y., Fang, L.M. and Lv, J. (2013) Establish a Comprehensive Evaluation System Combining Organizational Performance and Individual Performance in Public Hospitals. Chinese Hospital, 10, 26-28.

[11] Qin, Y.F. (2015) Difficulties and Countermeasures in the Secondary Distribution of Performance Wages in Public Hospitals. Chinese Hospital Management, 35, 53-54.

[12] Wang, H.S., Fu, L.J., Zhao, L.B. and Huang, J. (2016) Practice and Exploration of Performance Evaluation and Distribution Reform in Hospital Medical Technology Department. Chinese Hospital Management, 36, 55-57.

[13] Zhang, J., Meng, Y.F. and Luo, T. (2015) Practice and Reflection on Promoting Performance Management with Performance Communication. Chinese Journal of Hospital Administration, 31, 506-508. 